\title{
THE
}

1985

\section{Oscillations of Dynamic Topography in the Eastern Equatorial Pacific}

Laury Miller

University of Rhode Island

D. Randolph Watts

University of Rhode Island, randywatts@uri.edu

Mark Wimbush

University of Rhode Island, mwimbush@uri.edu

Follow this and additional works at: https://digitalcommons.uri.edu/gsofacpubs

Terms of Use

All rights reserved under copyright.

\section{Citation/Publisher Attribution}

Miller, L., Watts, D. R., \& Wimbush, M. (1985). Oscillations of Dynamic Topography in the Eastern Equatorial Pacific. Journal of Physical Oceanography, 15(12), 1759-1770. doi: 10.1175/ 1520-0485(1985)0152.0.CO;2

Available at: https://doi.org/10.1175/1520-0485(1985)0152.0.C0;2

This Article is brought to you for free and open access by the Graduate School of Oceanography at DigitalCommons@URI. It has been accepted for inclusion in Graduate School of Oceanography Faculty Publications by an authorized administrator of DigitalCommons@URI. For more information, please contact digitalcommons-group@uri.edu. 


\title{
Oscillations of Dynamic Topography in the Eastern Equatorial Pacific
}

\author{
LAURY MILLER, ${ }^{*}$ D. RANDOlPH WATTS AND MARK WIMBUSH \\ Graduate School of Oceanography, University of Rhode Island, Kingston, RI 02881
}

(Manuscript received 30 June 1983, in final form 27 June 1985)

\begin{abstract}
For 14 months in 1980-81, surface dynamic height was monitored with inverted echo sounders at five sites from 0 to $9^{\circ} \mathrm{N}$ along $110^{\circ} \mathrm{W}$. These records show that the SEC/NECC equatorial current system was welldeveloped during the boreal summer and fall, but weak and irregular during winter and spring when westward flow associated with the NEC extended as far south as $6^{\circ} \mathrm{N}$.

Superimposed on the mean dynamic topography of this region are energetic 20-to-80-day oscillations, longer periods being associated with higher latitudes. Near the equatorial ridge $\left(\sim 5^{\circ} \mathrm{N}\right)$, these oscillations have predominantly monthly periods, and amplitudes of $\sim 10 \mathrm{dyn} \mathrm{cm}$ comparable to the mean dynamic-height difference across the NECC. The broad in-phase meridional extent of these monthly oscillations implies that the principal mode of ridge variation is vertical undulation rather than meridional meandering, producing large in-phase monthly modulations in transport of the SEC and NECC.

Oscillations of the equatorial ridge are correlated with propagating $\sim 1000-\mathrm{km}$ wavelength sea surface temperature (SST) wave patterns observed in satellite infrared imagery. Passage of a northerly SST crest on the equatorial front at $110^{\circ} \mathrm{W}$ corresponds to a dynamic height minimum on the equatorial ridge. The relative phase and trochoidal shape of these crests is explained kinematically by superposition of the observed mean and oscillatory dynamic-height fields.
\end{abstract}

\section{Introduction}

Oscillations with time scales of about one month are a common feature in observations and in theoretical studies of the equatorial oceans. These observations include island sea level measurements (Wyrtki, 1978), repeated AXBT surveys (Barnett and Patzert, 1980), moored current and temperature records (Weisberg et al., 1979; Halpern, 1982), and surface drifter trajectories (Hansen and Paul, 1984).

The wave nature of the oscillations is dramatically illustrated by satellite infrared images (Legeckis, 1977; Legeckis et al., 1983), which show westward propagating disturbances in the sea surface temperature (SST) field in the eastern equatorial Pacific. Figure 1 shows schematically how these waves appear as deflections of the equatorial front, normally found just north of the equator between 90 and $120^{\circ} \mathrm{W}$. The waves have wavelengths of $800-1200 \mathrm{~km}$ and propagate westward at $1-2 \mathrm{~m} \mathrm{~s}^{-1}$, passing a fixed longitude at intervals of 13-35 days. A distinctive characteristic of these waves is their trochoidal shape; the crests (which extend $\sim 200$ $\mathrm{km}$ northward) are generally much sharper than the troughs.

Theoretical studies also exhibit equatorial wave phenomena with time scales of about one month. Philander $(1976,1978)$ shows that the high-shear region

* Present affiliation: NOAA National Geodetic Survey, Rockville, MD 20852. of the South Equatorial Current (SEC) north of the equator is barotropically unstable. For realistic shear values, this instability grows fastest at periods and wavelengths similar to those observed in the SST waves. Cox (1980) shows that this barotropic instability radiates energy downward and eastward from the surface shear zone in the form of equatorially trapped planetary waves. Semtner and Holland (1980) obtain similar trapped waves; however, in their numerical model these waves are generated by a baroclinic instability.

As part of the Equatorial Pacific Ocean Climate Study (EPOCS), we have made a 14-month investigation of the equatorial current system north of the equator at $110^{\circ} \mathrm{W}$. A meridional array of five inverted echo sounders (IES; Watts and Rossby, 1977) was deployed between 0 and $9^{\circ} \mathrm{N}$, from September 1980 through October 1981 , to monitor the seasonal and shorter-period fluctuations in the dynamic topography across the North Equatorial Countercurrent (NECC) and the northern portion of the SEC. This paper discusses the very energetic 20 - to 80 -day oscillations that were found to be prominently superimposed on the longer-term variations. The following sections present these observations and describe their temporal and spatial variability. The occurrence of dynamic height lows is shown to coincide with the passage of northerly crests in the SST field. A kinematic model is presented which explains the form and phase of the SST waves. Finally, various other equatorial wave observations are interpreted within the framework of this model. 


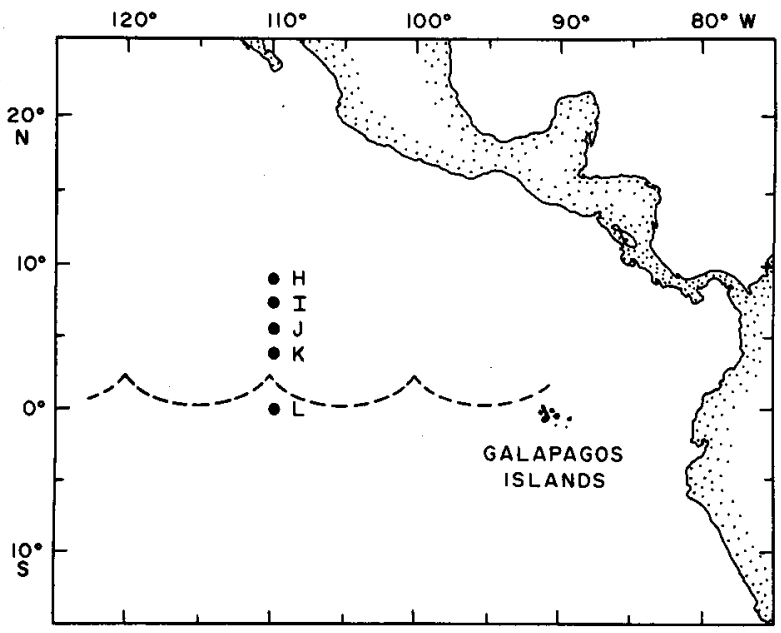

FIG. 1. Map showing locations of the five inverted echo sounders (IES) along $110^{\circ} \mathrm{W}$ at $0,4.5,6,7.5$ and $9^{\circ} \mathrm{N}$ (sites $\mathrm{L}$ to $\mathrm{H}$, respectively). A schematic example of the sea-surface-temperature (SST) front is indicated by the dashed line.

\section{Observations}

Five IESs were deployed in a meridional array, at 0 , $4.5,6,7.5$, and $9^{\circ} \mathrm{N}$ (sites $\mathrm{L}, \mathrm{K}, \mathrm{J}, \mathrm{I}$, and $\mathrm{H}$, respectively) along $110^{\circ} \mathrm{W}$ (Fig. 1) in August-September 1980 . During February-March 1981 the instruments at 0, 4.5 , and $6^{\circ} \mathrm{N}$ were recovered and replaced; the one at $7.5^{\circ} \mathrm{N}$ was lost, and a new instrument was deployed there; the IES at $9^{\circ} \mathrm{N}$ was left in place. The five instruments were recovered in October 1981 .

A meridional section of the mean surface dynamicheight topography along $110^{\circ} \mathrm{W}$, based on nine CTD sections taken by Hayes et al. (1983), is shown in Fig. 2 with our IES site locations added. Instrument $\mathrm{K}$ is seen to be located almost directly beneath the mean position of the equatorial ridge that separates the eastward flowing NECC to the north from the westward flowing SEC. Instrument $J$ was located halfway down the NECC side of the ridge. Instruments I and $\mathrm{H}$ were within the broad trough that separates the NECC to the south from the North Equatorial Current (NEC) to the north. (Farther north, the dynamic height rises across the NEC.) Our dynamic height records from sites $\mathrm{H}$ through $\mathrm{K}$ resolved the meridional structure of the NECC well during most of the experiment.

The SEC was sampled at two sites: $K$, beneath the equatorial ridge, and $\mathrm{L}$, on the equator near the mean position of the equatorial trough. The slight $\left(1^{\circ}\right)$ displacement of the trough south of the equator is consistent with direct velocity observations showing a narrow band of eastward surface flow just south of the equator (Leetmaa, 1982). To determine how the dynamic topography behaves in the $500 \mathrm{~km}$ region between sites $K$ and $L$, linear regressions with latitude were computed for eight CTD sections between 0 and $4.5^{\circ} \mathrm{N}$, with half-degree station spacing. The results (Table 1) indicate a high degree of linearity for both the individual (synoptic) sections and the mean section. These results are used later to justify the linear interpolation of the dynamic topography between observations at $K$ and $L$.

The IES acoustic travel-time measurements were converted to dynamic heights by a simple linear rescaling, as described in the remainder of this section.

The scale factor for IES record $\mathrm{L}\left(0^{\circ}\right)$ was determined by a direct comparison with moored temperature measurements. During the first five months of the IES experiment, simultaneous temperature measurements were made at twenty depths on two EPOCS moorings located near site L: mooring T8 $(20,30,40,50,90$, $100,110,120,140,150,175,200,250 \mathrm{~m})$, and mooring E3 (427, 727, 927, 1027, 2027, 2127, 3027 m). Each temperature time series was converted to a density time series using a mean $T-S$ curve to infer salinity. The entire dataset was then vertically integrated to produce a surface dynamic-height time series $(20 \mathrm{~m}$ referenced to $3027 \mathrm{~m}$ ). The linear regression of IES record $\mathrm{L}$ on this dynamic height series produced a slope of -4.70 dyn $\mathrm{cm} \mathrm{ms}^{-1}$ with a correlation coefficient $(r)$ of 0.87 .

This result was confirmed by a second computation based on ten surface-to-bottom CTD profiles taken near site $L$ (but not during the IES experiment). Surface-to-bottom dynamic heights and simulated acoustic travel times were computed for these stations. The linear regression of these two quantities produced a slope that is not significantly different from that derived from the two temperature moorings.

The scaling factors for sites $\mathrm{H}$ through $\mathrm{K}$ were determined from CTD profiles by the procedure just described. All EPOCS CTDs taken during the years 1979 81 were grouped by latitude and then regressed (dy-

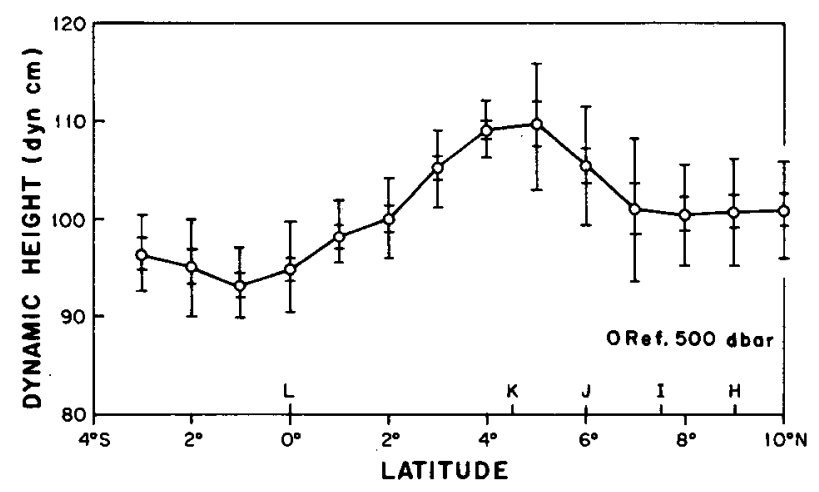

FIG. 2. Meridional section of mean surface dynamic height relative to $500 \mathrm{db}\left(D_{0.500}\right)$ as a function of latitude along $110^{\circ} \mathrm{W}$. The open circles at half-degree intervals are averages of nine CTD sections taken at irregular time intervals over three years by Hayes et al. (1983). The larger error bars indicate the standard deviation; the smaller error bars indicate the standard deviation of the mean. IES sites $\mathrm{L}$ through $\mathrm{H}$ are also shown. 
TABLE 1. Correlation coefficients, $r$, resulting from linear regressions of surface dynamic height (relative to $500 \mathrm{db}$ ) with latitude between 0 and $4.5^{\circ} \mathrm{N}$ along $110^{\circ} \mathrm{W}$, based on the data of Hayes et al. (1983).

\begin{tabular}{cc}
\hline \hline Section date & $r$ \\
\hline Feb 79 & 0.92 \\
May 79 & 0.96 \\
Oct 79 & 0.94 \\
Mar 80 & 0.92 \\
Aug 80 & 0.98 \\
Sep 80 & 0.95 \\
Mar 81 & 0.87 \\
Jun 81 & 0.97 \\
Mean & 0.99 \\
\hline
\end{tabular}

namic height verus simulated acoustic travel time) over the range 0-950 db. (Surface-to-bottom CTDs were taken only at the equator.) The scale factors at sites $\mathrm{H}$, $\mathrm{I}$, and $\mathrm{J}$ were indistinguishable. Therefore, all CTD data between 5.5 and $9.5^{\circ} \mathrm{N}$ were combined and a single scale factor, -8.77 dyn $\mathrm{cm} \mathrm{ms}^{-1}$, was computed for these three sites. The scale factor for site $\mathrm{K}$ was determined by the same procedure to be -7.36 dyn $\mathrm{cm}$ $\mathrm{ms}^{-1}$. By comparison with the equator, we estimate that the surface to 950 -db scale factors at sites $\mathrm{H}$ through K may overestimate variations of the total dynamic heights (surface to bottom) by as much as $20 \%$.

An offset is also required in the linear rescaling to convert acoustic travel time to dynamic height. This was determined at each site by setting the mean of each IES record equal to the mean surface dynamic height at the corresponding latitude in Fig. 2. The inverted echo sounder responds to dynamic height variations through the entire water column, and the scaled acoustic travel-time records are here referred to as "surface dynamic height." Only the offsets have been referenced to $500 \mathrm{db}$ to be consistent with the transport data reported by Hayes et al. (1983).

\section{Results}

\section{a. Time series}

The surface dynamic-height time series from the IES array along $110^{\circ} \mathrm{W}$ are presented in Fig. 3. All of these records exhibit large amplitude $(10-20$ dyn $\mathrm{cm}$ ) oscillations with time scales of a month or more. The prominent periodicities of the oscillations lengthen with

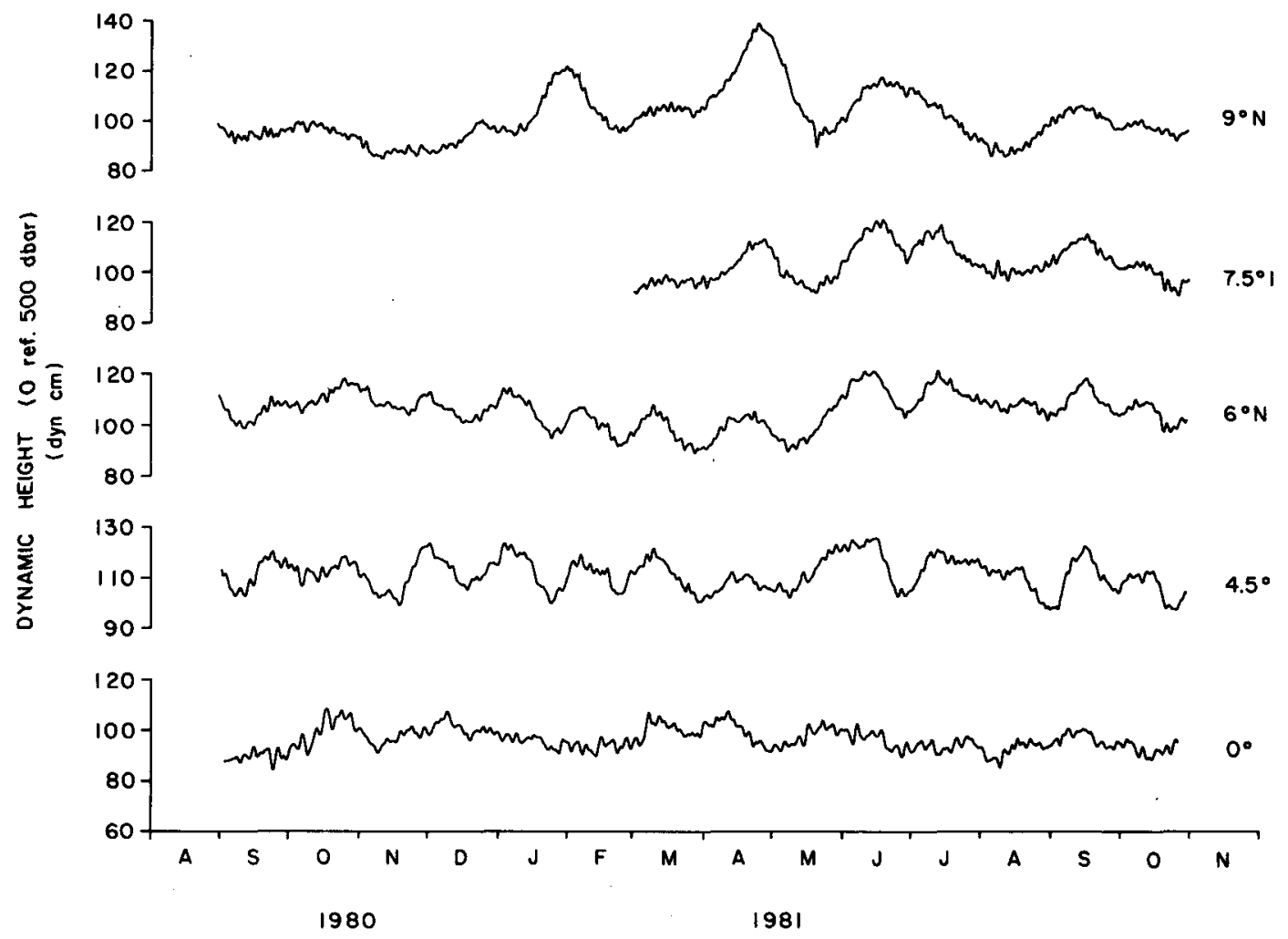

FIG. 3. Time series of surface dynamic height at each IES site. The acoustic travel-time measurements were 24-hour low-pass filtered and rescaled to dynamic height as described in the text. 
increasing latitude. The equatorial record shows a few $\sim 15$ dyn $\mathrm{cm}$ peaks of $\sim 1$ month duration (e.g., October 1980, December 1980, March-April 1981). At 4.5 and $6^{\circ} \mathrm{N}$ the oscillations are most energetic at periods of 30-40 days, whereas the records from 7.5 and $9^{\circ} \mathrm{N}$ are most energetic at periods of 60-80 days. This increase in time scale appears to be rather smooth; indeed, many fluctuations appear coherently across several (or even all) records (e.g., October 1980, April 1981, September 1981). The nonstationarity of these records is also noteworthy; at 4.5 and $6^{\circ} \mathrm{N}$, the 30 -day oscillations are extremely regular from September 1980 to March 1981 and less obvious later; at $9^{\circ} \mathrm{N}$ the 60 to 80-day oscillations are far more prominent in the middle portion (February-August 1981) than at the beginning or end.

The dynamic topography of the sea surface along $110^{\circ} \mathrm{W}$ is contoured from the IES records in a latitudeversus-time plot (Fig. 4). At any latitude in this figure, the surface zonal velocity is inversely proportional to the meridional contour spacing, and the surface layer transport (relative to the abyssal layer) is proportional to the number of contours crossed. The proportionality factor changes with latitude (Hayes et al., 1983). Proceeding from south to north in Fig. 4, one clearly sees (i) the westward flowing SEC with the topography rising to a ridge generally near $4.5^{\circ} \mathrm{N}$, (ii) the eastward flowing NECC with the topography falling to a trough often extending beyond $9^{\circ} \mathrm{N}$, and (iii) a time interval (February-May 1981) when the westward flowing NEC is evident as a rise in the topography north of $6^{\circ} \mathrm{N}$. The boundary between the NEC and the NECC migrated southward to $\sim 6^{\circ} \mathrm{N}$ during January and northward again during May and June. During this time the NECC was narrow and its transport low. The SEC also showed evidence of weakening particularly in March and April. Hence, these data support the historical notion that both the SEC and NECC are weak during winter-spring and strong during summer-fall in the eastern Pacific (Tsuchiya, 1974).

During March and April 1981, when the SEC/NECC current system was weakest, the surface dynamic height signal at the equator showed a pair of high peaks $(\sim 15$ dyn $\mathrm{cm}$, Fig. 3 one month apart. Hayes and Halpern (1984) report a double pulse of eastward transport in the upper $200 \mathrm{~m}$ at $0^{\circ}, 110^{\circ} \mathrm{W}$ at this same time, followed about 10 days later at the Galapagos Islands by a $\sim 15 \mathrm{~cm}$ peak in sea level of comparable duration. On the basis of the observed eastward phase speed of $2.3 \mathrm{~m} \mathrm{~s}^{-1}$, Hayes and Halpern (1984) identify this as a first baroclinic-mode Kelvin wave. The passage of this feature at $0^{\circ}, 110^{\circ} \mathrm{W}$ coincided with other events off the equator. At this time, the IESs at 4.5 and $6^{\circ} \mathrm{N}$ recorded their lowest dynamic height of the entire 14 months, which was presumably related to seasonal weakening of the local wind field. This time period also coincided with the nonstationary change in oscillations described in the first paragraph of this section.

In addition to the seasonal time-scale variations discussed above, the 20- to 80-day oscillations also strongly affect the dynamic topography in Fig. 4. The monthly oscillations can be seen clearly on the equatorial ridge near $4.5^{\circ} \mathrm{N}$ : the entire ridge appears to rise and fall rather than meander north and south. These vertical displacements extend coherently, in many cases, at least from the equator to $9^{\circ} \mathrm{N}$, and have large amplitudes (10-20 dyn $\mathrm{cm}$ ), comparable to the mean topography across this region. Hence, the monthly oscillations produce large modulations in the local transports of the SEC and NECC.

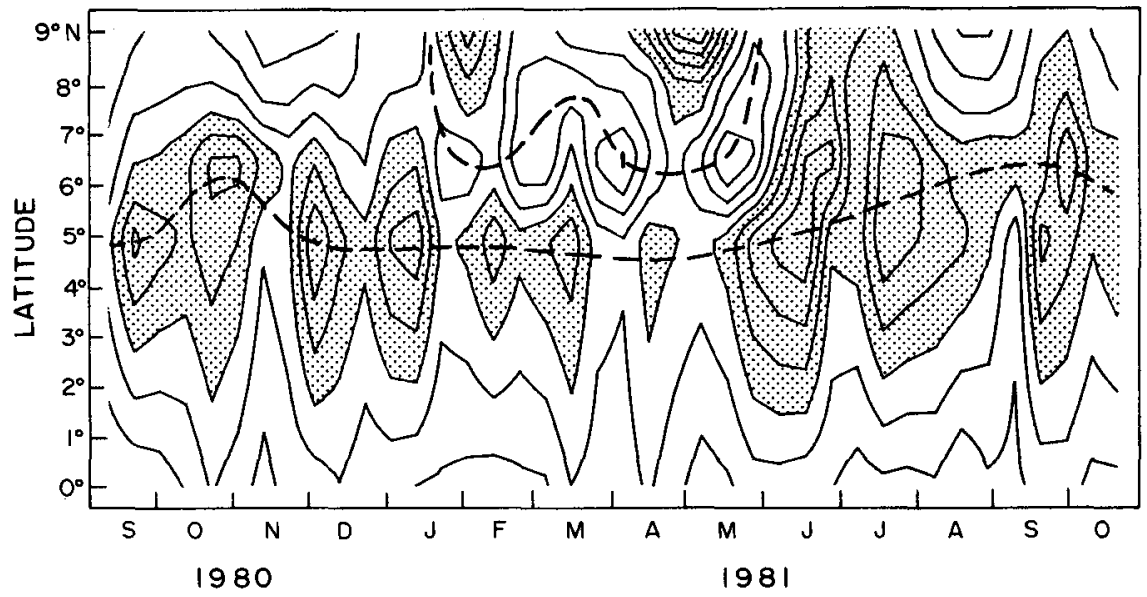

FIG. 4. Surface dynamic height determined by IESs along $110^{\circ} \mathrm{W}$, plotted as a function of latitude and time. Contour interval is $5 \mathrm{dyn} \mathrm{cm}$. Stippled areas represent values greater than 105 dyn $\mathrm{cm}$. The data are linearly interpolated between the IES sites. The two dashed curves delineate the SEC/NECC dynamic height ridge (lower line) and the NECC/NEC trough (upper line). 


\section{b. Spectra}

The IES-derived surface dynamic-height spectra are contour-plotted as a function of frequency and latitude in Fig. 5. This figure shows quantitatively the restricted frequency band in which the oscillations are concentrated, together with a trend toward lower frequencies at higher latitudes. Near the equatorial ridge $\left(\sim 5^{\circ} \mathrm{N}\right)$, the oscillations are most energetic at periods of 30-40 days. Between 6 and $8^{\circ} \mathrm{N}$, the maximum spectral energy declines somewhat, and the dominant periods are $40-60$ days. Between 8 and $10^{\circ} \mathrm{N}$, the maximum spectral energy reaches its highest level, and the dominant periods are 60 to 80 days. A separate small spectral peak appears on the equator at a period of 5.5 days in the inertia-gravity band.

As mentioned earlier, the spectral characteristics of the low-frequency oscillations are not stationary over the lengths of the records. To emphasize this point, we show in Figs. 6 and 7 the spectra of dynamic height from the meridional region $\left(4.5-6^{\circ} \mathrm{N}\right)$ of the 30 - to 40 day energy peak in Fig. 5, for the first and last nine months of the experiment (overlapping by four months), respectively. During the first nine months, the spectrum is virtually monochromatic, at a period of 34 days (Fig. 6). During the last nine months, the total energy is about the same, but the spectrum is now split into three lesser peaks at periods of approximately 49, 30 and 23 days (Fig. 7).

\section{c. Dynamic topography and SST waves}

In this section we consider the relationship between the dynamic topography oscillations described above and the SST waves observed in a series of daily satellite images (Legeckis, 1983). Figure 8 shows the development of a train of SST waves during one month (preceding the IES deployment), chosen to illustrate the variety of phase speeds that may coexist. The SST front typically has broad troughs extending to the equator and trochoidal crests reaching $3^{\circ} \mathrm{N}$. Successive positions of what appear to be the same three crests are joined by the lines A, B, and C. Crests A and C are representative of the features reported by Legeckis (1977), in that they have westward phase speeds of 30$50 \mathrm{~km} \mathrm{~d}^{-1}$, and zonal separations of $1000-1200 \mathrm{~km}$. Crest $\mathrm{B}$ is unusual in that it appears to be propagating much faster $\left(100 \mathrm{~km} \mathrm{~d}^{-1}\right)$ than the two neighboring crests.

Figure 9 compares the passage of SST crests at $110^{\circ} \mathrm{W}$ with the dynamic height record from $4.5^{\circ} \mathrm{N}$ (K), the nearest off-equator site to the SST front. The unfiltered record is shown at the bottom, and two bandpass-filtered versions are shown at the top: the middle curve is band-centered at 34 days to correspond to the dominant spectral peak during the first nine months of the experiment (Fig. 6), and the upper curve is bandcentered at 23 days to correspond to the shortest-period spectral peak during the last nine months of the ex-

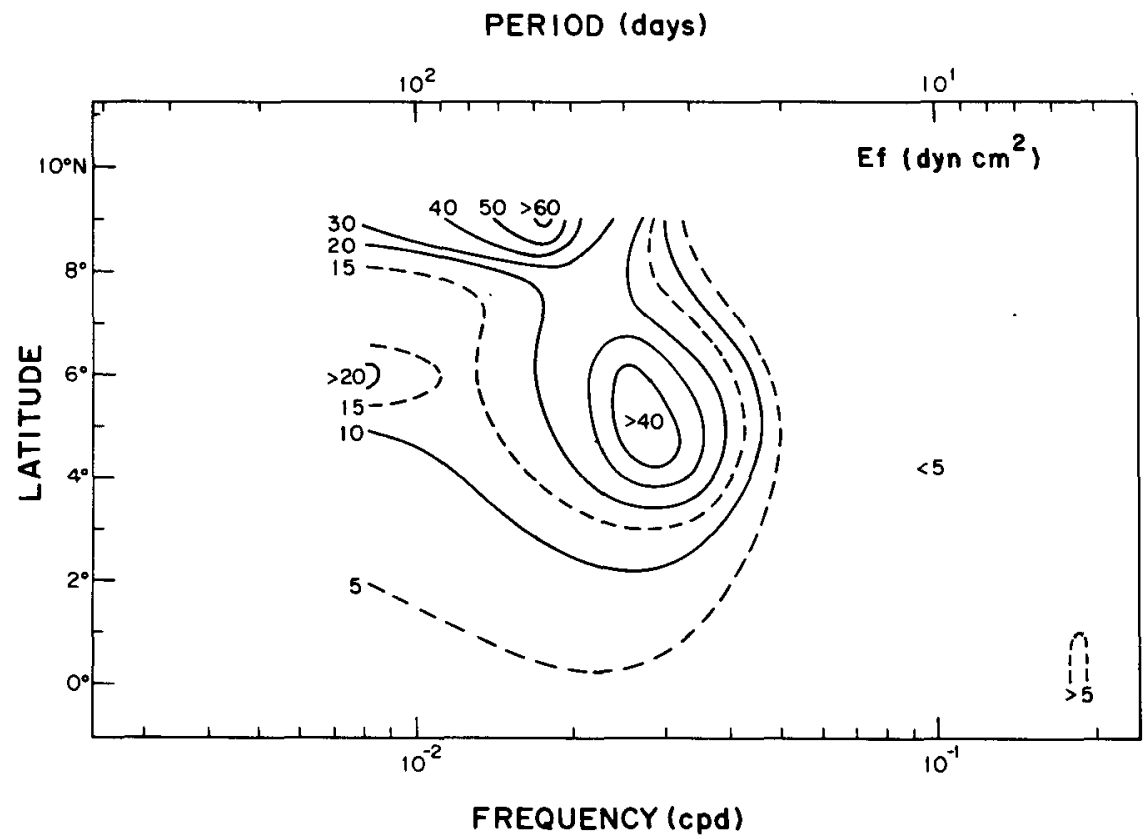

FIG. 5. Spectra of dynamic height records determined by IESs along $110^{\circ} \mathrm{W}$, plotted as a function of latitude and frequency. Spectral levels are plotted in energy-preserving form, $E f$ (dyn $\mathrm{cm})^{2}$ versus $\log f$. 


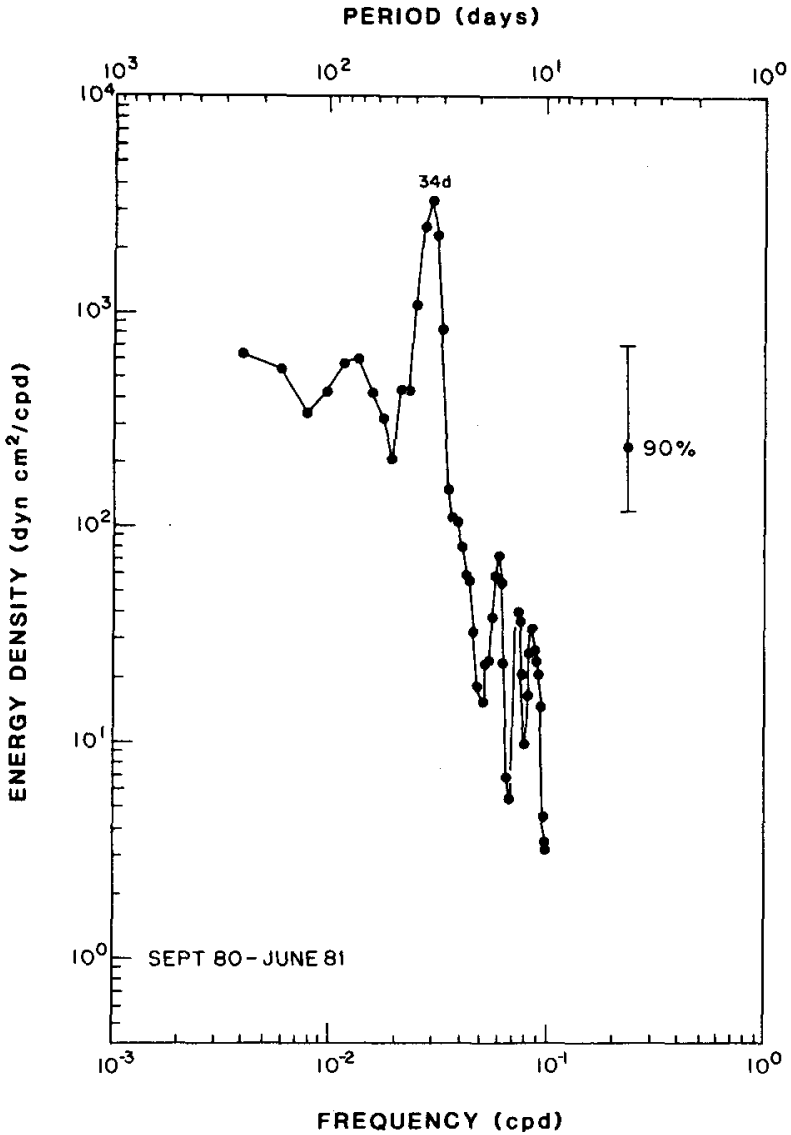

FIG. 6. Spectrum of dynamic height near the SEC/NECC dynamicheight ridge crest (average of records at $\mathrm{K}$ and $\mathrm{J}$ ) for the interval September 1980-June 1981 . The $90 \%$ confidence interval shown is based on 7 degrees of freedom.

periment (Fig. 7). In the fall of 1980, we see (Fig. 9) that SST crests D, E, and G crossed longitude $110^{\circ} \mathrm{W}$ at times corresponding to dynamic height minima in the 34-day band. The one exception to this pattern was SST crest F. A close examination of the SST data reveals that crest $F$ traveled at a significantly higher speed than either crest $E$ or $G$; thus crest $F$ may represent an anomalous wave for this time interval, similar to crest B in Fig. 8.

In contrast, during the summer and fall of 1981, the correspondence between the passage of SST crests and the dynamic height oscillations appears to be best in the 23-day band. Indeed, it is striking that during this time interval both the 23-day dynamic height oscillations and the SST waves began at the same time in June, and executed exactly seven cycles. The relative phasing was somehwat irregular (presumably because the 30- to 40-day oscillations disturbed the SST pattern) but crest passages were generally within the quarter cycle following the dynamic height minima.

These pieces of observational evidence indicate that the 20- to 40-day dynamic height and SST front oscillations are manifestations of the same phenomenon; hence it is reasonable to conclude that the dynamic height oscillations have the same $\sim 1000 \mathrm{~km}$ wavelength associated with the SST waves. In the next section we briefly discuss a possible energy source for this wave motion.

\section{d. Comparison with theory}

As mentioned in the introduction, there are several theoretical studies which predict that instabilities in the equatorial current system will produce monthly period, $\sim 1000 \mathrm{~km}$ wavelength oscillations in the equatorial region. In particular, Philander (1976) uses a one-and-a-half layer model to show that both the $\beta$ effect and divergence tend to destabilize westward flows. As a result, the high-shear region on the northern side of the SEC velocity maximum is especially susceptible to instability. For a mean meridional profile of zonal velocity, $\bar{U}(y)$, from the equatorial Atlantic, Philander (1978) determined that westward propagating waves will develop with period about 30 days and wavelength

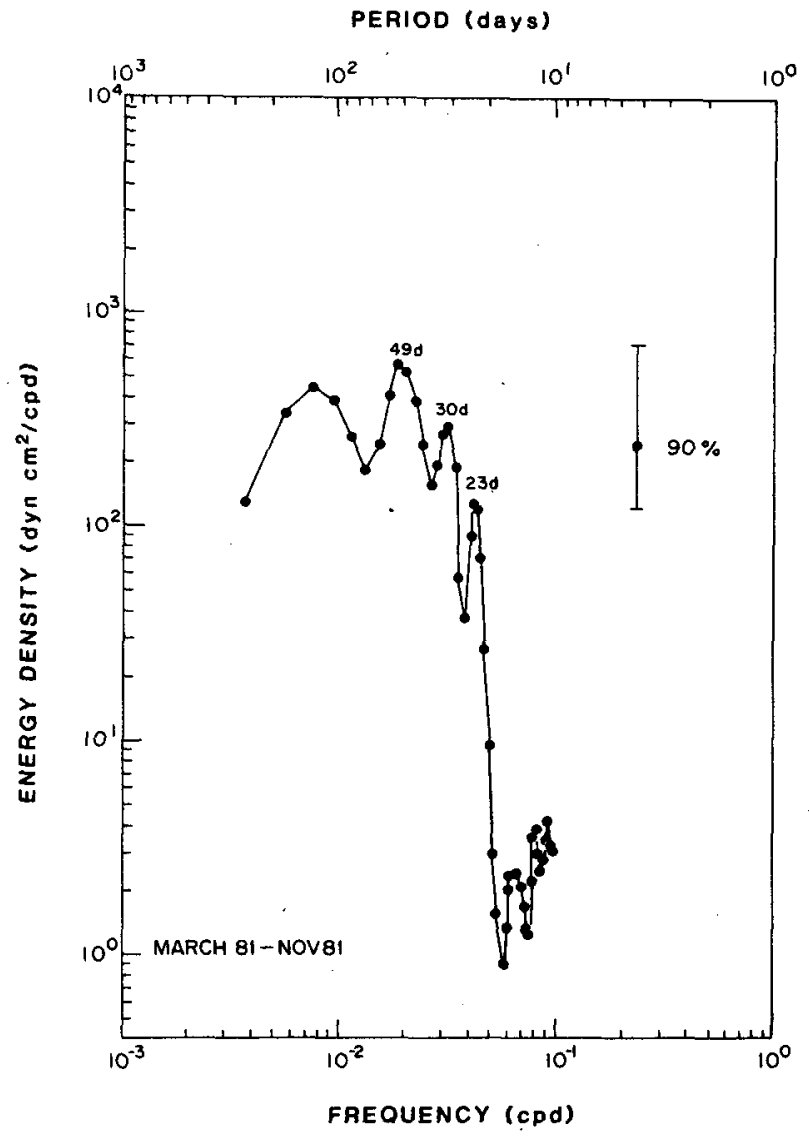

FIG. 7. Spectrum as in Fig. 6, but for a later interval, March 1981-November 1981. 


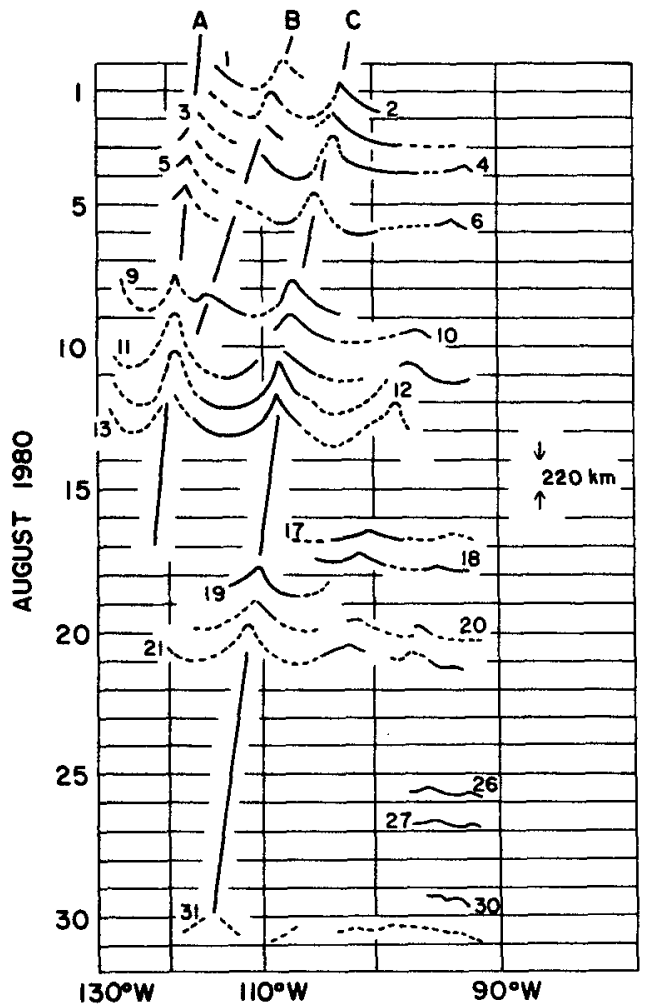

FIG. 8. Space-time plots of SST front in the eastern equatorial Pacific, August 1980, based on satellite infrared data (Legeckis, personal communication, 1983). Horizontal lines represent the equator, offset $220 \mathrm{~km}$ downward on each successive day. Abscissa is longitude. SST crests are denoted by phase lines A, B, C.

about $1100 \mathrm{~km}$. Since the model output is sensitive to the form of the $\bar{U}(y)$ profile, which differs significantly between the Atlantic and Pacific equatorial regions, it is inappropriate to compare Philander's Atlantic perturbation pressure field, $P^{\prime}$, with our observations. Consequently, we have applied Philander's (1976) model to a $\bar{U}(y)$ profile for the eastern equatorial Pacific reported by Hansen and Paul (1984) from a 140-day average of buoy-drift data (details are provided in the Appendix).

For Hansen and Paul's $\bar{U}(y)$ profile, the fastestgrowing instability has 23-day period and $860-\mathrm{km}$ zonal wavelength. In Fig. 10 , the $P^{12}$ field of this unstable wave is compared with the IES-observed meridional distribution of dynamic-height variance in the 23-day band. The model $P^{\prime 2}$ is asymmetrically distributed, with a broad maximum at $2-6^{\circ} \mathrm{N}$, and a much less energetic peak at $2-3^{\circ} \mathrm{S}$. The observations roughly match this distribution north of the equator; no observations are available to the south.

The observed dynamic height variance is also strongly peaked in the 34-day band; however, a different $\vec{U}(y)$ profile is required to produce unstable waves with the appropriate wavelength at 34-day period. As shown in the Appendix, a $20 \%$ reduction in the amplitude of $\bar{U}$ produces a near-maximum-growth wave with period 34 days and wavelength $1000 \mathrm{~km}$. In Fig. 11 the $P^{\prime 2}$ field of this unstable wave is compared with the observed meridional distribution of dynamic height variance in the 34-day band. Again both the $P^{\prime 2}$ curve and the observations are broadly peaked in the region $2-6^{\circ} \mathrm{N}$.

Since the 23-day period is robust for rescalings of $\bar{U}(y)$ within $15 \%$ of the observed form (see dashed line in Fig. 15a), the procedure to produce a 34-day instability in the model is somewhat arbitrary. We therefore also consider the possibility that the waves may be equatorially trapped free Rossby waves at this period.

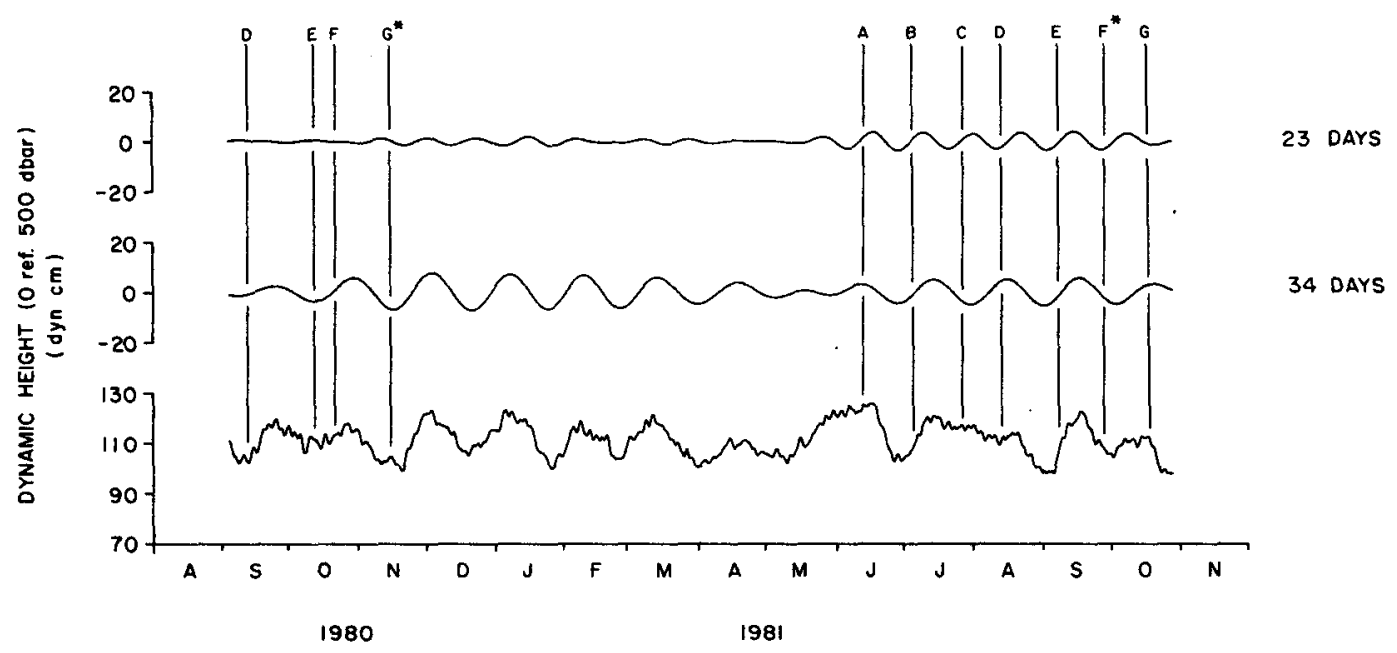

FIG. 9. Surface dynamic-height record $\mathrm{K}\left(4.5^{\circ} \mathrm{N}\right)$. Separate curves represent (from bottom to top): original (24-hour low-pass) record, 34-day band pass, 23-day band pass. Vertical lines represent times when SST crests pass $110^{\circ} \mathrm{W}$; asterisk denotes space-time extrapolation. 


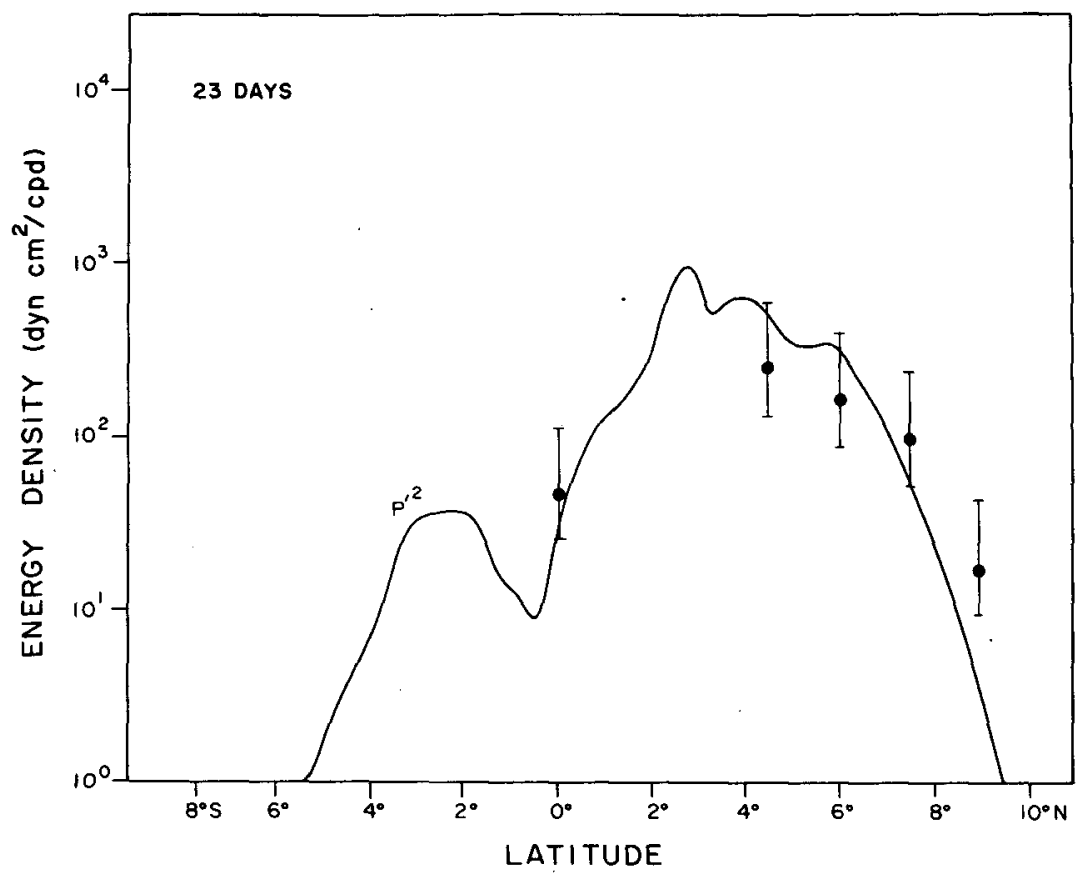

FIG. 10. Meridional distribution of dynamic-height energy density in band centered on 23 days. Solid dots represent IES observations during the interval February-October 1981. Error bars indicate $90 \%$ confidence limits for 7 degrees of freedom. Solid curve represents $P^{\prime 2}$ for a 23-day, 864-km instability wave computed as described in Appendix from Philander's (1976) model. $P^{\prime 2}$ curve is scaled to fit observations.

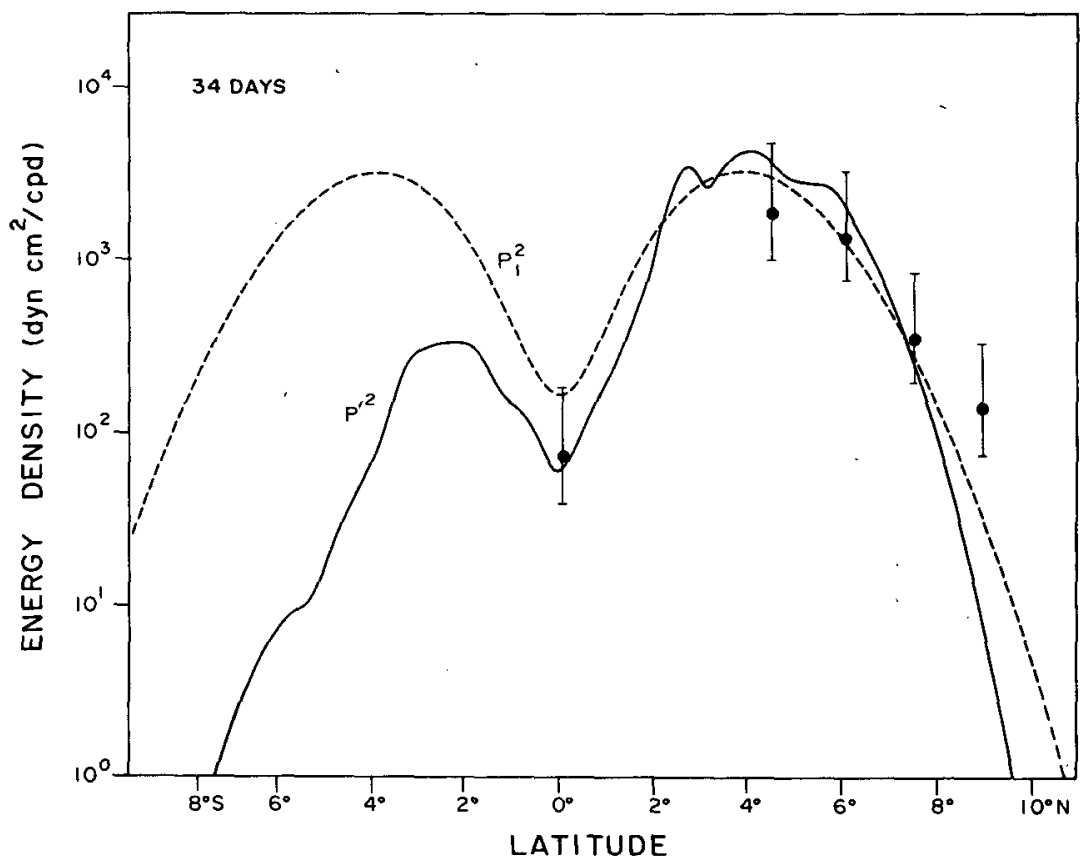

Fig. 11. Meridional distribution of dynamic-height energy density in band centered on 34 days. Solid dots represent IES observations during the interval September 1980-June 1981. Error bars indicate $90 \%$ confidence limits for 7 degrees of freedom. Solid curve represents $P^{\prime 2}$ for a 34-day, $1000-\mathrm{km}$ instability wave computed as described in Appendix. Dashed curve represents $P_{1}^{2}$ for a 34-day, $1000-\mathrm{km}$ Rossby wave (first meridional mode, first vertical mode, assuming separation parameter $C_{1}=2.2 \mathrm{~m} \mathrm{~s}^{-1}$ ). $P^{2}$ and $P_{1}^{2}$ curves are scaled to fit observations. 


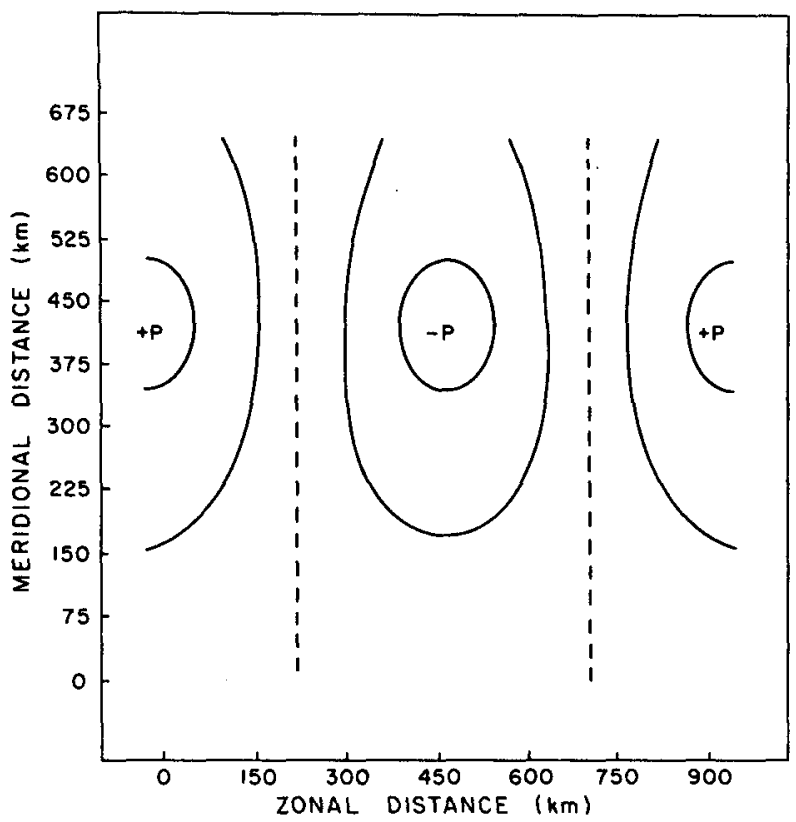

FIG. 12. Schematic pressure field $P^{\prime}$ representing observed oscillations.

In Fig. 11 the squared Hermite function of the first meridional-mode Rossby wave, $P_{1}{ }^{2}$, is also shown. Within the region of our observations, the $P^{2}$ profiles at 34 days for the instability model and the Rossby wave are very similar; however, south of the equator the instability amplitude is small, whereas the Rossby wave amplitude remains large. Because of the similarity of the unstable- and free-mode shapes, the former may excite the latter, in which case the IES signal would represent the sum of both types of oscillation.

\section{e. Kinematic model of SST waves}

Up to this point in the analysis, we have used the hypothesis that the trochoidal waves in the SST data and the low-frequency oscillations in the IES data are indicative of the same wave phenomenon, without actually providing a mechanism linking the two. In this section we show that one can, in fact, construct a kinematic model of the SST front by simply adding to the mean pressure field associated with the equatorial ridge an oscillatory $P$-field with zonal wavelength $1000 \mathrm{~km}$ and meridional dependence similar to that observed.

We illustrate this model construction in Figs. 12, 13, and 14 using a schematic representation of the mean pressure field $\left(P_{\text {mean }}\right)$ and the oscillations $\left(P^{\prime}\right)$. Figure 12 shows a $P^{\prime}$ field corresponding roughly to the observed and theoretical modes shown in Figs. 10 and 11 . Figure 13 shows a sloping meridional pressure distribution $\left(P_{\text {mean }}\right)$ which simulates the mean thermocline rise towards the equator; the meridional $P^{\prime}$ amplitude dependence is also shown. Figure 14 presents the sum of $P_{\text {mean }}$ and $P^{\prime}$. The stippled area in Fig. 14 indicates a region in which relatively low-temperature isotherms intersect the sea surface. The boundary of this region has a trochoidal shape similar to that of the SST front in the satellite images. Furthermore, the crest in the model points northward into a dynamic height minimum. The same correspondence of SST crest with dynamic height minimum was noted earlier, in observations presented in Fig. 9. Hence, the trochoidal SST pattern need not be a dynamic feature of these waves, but can be explained as a simple kinematic result. This mechanism works for any sequence of highs and lows that have the appropriate amplitude and structure within $0-5^{\circ} \mathrm{N}$ and the observed wavelength and phase speed.

\section{Discussion and conclusions}

The IES observations and kinematic model presented above can be used to help clarify the interpretation of several other studies of short-term variability in the equatorial Pacific.

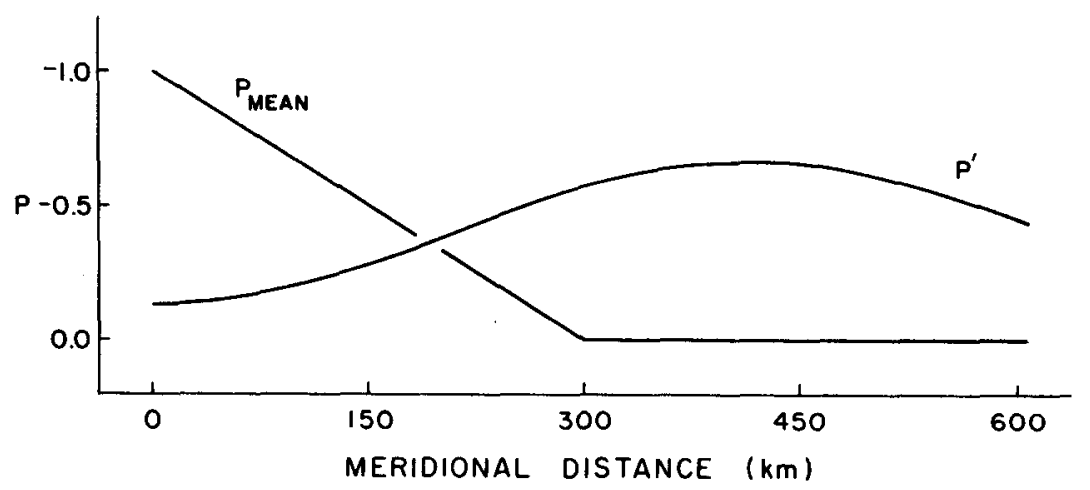

FIG. 13. Schematic profile of average pressure field, $P_{\text {mean }}$, simulating the thermocline rise towards the equator. The meridional structure of appropriate relative $P^{\prime}$ amplitude is also shown. 


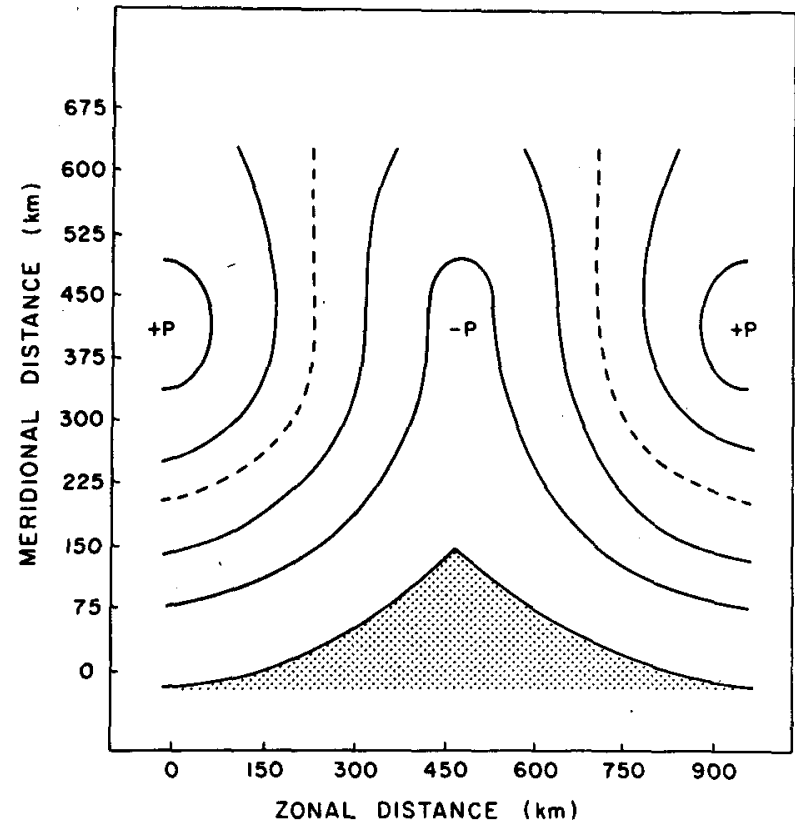

Fig. 14. Schematic total pressure field from summing $P_{\text {mean }}$ and $P^{\prime}$ of Figs. 12 and 13. Stippled area represents region where cooler water appears at the sea surface.

\section{a. Equatorial ridge}

Short-term fluctuations in the structure of the equatorial ridge separating the SEC and NECC have previously been observed in the central Pacific. Wyrtki (1978) related monthly $10-\mathrm{cm}$ amplitude fluctuations in sea level at Fanning Island $\left(4^{\circ} \mathrm{N}, 159^{\circ} \mathrm{W}\right)$ to lateral oscillations of a satellite-tracked surface drifter traveling eastward in the NECC. He concluded that the equatorial ridge meanders at times over large $(200-300 \mathrm{~km})$ latitudinal distances on a monthly time scale. The IES measurements, although made much farther to the east and at another time, suggest a different interpretation. Instead of the principal mode of ridge variation being a north-south meandering motion, it could be a vertical motion (as in Fig. 4), and this would still be consistent with Wyrtki's (1978) tide gage and drifter observations.

\section{b. Surface drifter trajectories}

Having a model that describes how the equatorial ridge behaves also helps explain other more complicated drifter trajectories. For example, Hansen and Paul (1984) report several cases of surface drifters undergoing large amplitude $(500 \mathrm{~km})$, eddylike motions in the same latitudinal band as the equatorial ridge (2$6^{\circ} \mathrm{N}$ ), each following an anticyclonic pattern. The fact that these drifters rotated clockwise can be explained by the particular way in which the model mean and fluctuating pressure fields combine. As long as the two fields have similar meridional length scales and the amplitude of the fluctuating pressure field is less than the increase of the mean pressure associated with the ridge, the sum of the two will always be a series of high pressure, anticyclonic disturbances propagating along the ridge. These pressure disturbances are represented by the closed contours in Fig. 14. It follows that a surface drifter that is deployed near the ridge crest will tend to move in a closed anticyclonic pattern, while a drifter that is deployed on either flank of the ridge (where the contours in Fig. 14 are not closed) will tend to move in a north-south meandering motion.

\section{c. SST waves}

Three questions about the SST waves need to be answered. First, are the waves intrinsically related to the dynamics of the SST front, or are they coincidental, in the sense that they are superimposed on the front? Second, what is the significance of their trochoidal shape, and does it imply, as Philander (1978) suggests, the presence of nonlinearities? Third, what is the significance of the fact that the SST waves appear in the satellite images only from 90 to $120^{\circ} \mathrm{W}$ north of the equator and only from May to December?

The first question is answered by the observations in Fig. 9 and the model presented above. The fact that Fig. 9 shows $\sim 30$-day oscillations in the dynamic height field during the months of December-March, when the SST front is either absent or too weak to appear in the satellite observations, suggests that the dynamic height oscillations are not directly dependent on the presence of the front. As the kinematic model shows, however, the front (when present) responds to the dynamic height oscillations.

The model provides a simple linear explanation for the trochoidal shape of the waves. Trochoidal features can be generated simply by having a mean pressure field and a series of pressure oscillations with amplitudes and meridional scales similar to those observed (section 3e).

Finally, several aspects of the space-time distribution of the SST waves can be explained in terms of the underlying assumptions regarding the mean density field in the model. In this region, the thermocline rises and forms a sharp SST front just north of the equator during the summer-fall months, whereas to the south the meridional SST gradient is always diffuse (Wyrtki, 1964). This meridional asymmetry in the observed surface temperature field arises from the fact that the winds in the eastern equatorial Pacific are predominantly northward and strongest during the months of MayDecember -(Hastenrath and Lamb, 1977), thus producing a broad divergence zone south of the equator and a narrow convergence zone north of the equator. This local wind-forcing mechanism explains the seasonal intensification of the SST front and its presence 
just north of the equator. To explain the disappearance of the front west of $120^{\circ} \mathrm{W}$, one must also account for the fact that the mean winds are predominantly westward in that region. This causes a setup of surface water along the equator, and consequently a westward deepening of the thermocline beyond the upwelling reach of the local winds. It follows that SST waves appear in the satellite images only when and where an SST front exists owing to the effects of the seasonally and spatially varying winds on the mean density structure.

In summary, this experiment represents the first time that the surface dynamic topography has been continuously monitored along a meridian in the equatorial Pacific. The observations show, in addition to seasonal trends in the SEC/NECC current system, large-amplitude, spatially coherent oscillations with 3week to 3-month time scales extending throughout the array (from 0 to $9^{\circ} \mathrm{N}$ ). These energetic short-term variations have amplitudes comparable to the mean dynamic-height differences across this region, and thus should be considered in the sampling design of any monitoring program in the equatorial oceans.

Acknowledgments. Richard Legeckis, Donald Hansen, Stanley Hayes, David Halpern, and Robert Weisberg generously shared their results with us prior to publication. George Philander gave us valuable advice, and the computer code for his barotropic instability model. Gerard Chaplin and Michael Mulroney provided engineering help with the inverted echo sounders. This work was supported by the Equatorial Pacific Ocean Climate Studies (EPOCS) project of NOAA.

\section{APPENDIX}

\section{Model Calculation}

This appendix describes details of our calculations using Philander's (1976) barotropic instability model (linear, one-and-one-half layer, equatorial $\beta$-plane) together with Hansen and Paul's (1984) meridional profile of mean zonal velocity, $\bar{U}(y)$. The Hansen and Paul profile (their Fig. 4) is based on measurements made by 20 satellite-tracked surface drifters in the region $10^{\circ} \mathrm{S}-10^{\circ} \mathrm{N}, 100-130^{\circ} \mathrm{W}$, over 140 days in 1979 (one year before the IES observations). Although this represents a fairly large collection of data for one year, substantial variations in the strength of the mean zonal currents are known to occur seasonally and from year to year in this region (Hayes et al., 1983).

We have attempted to represent these variations in our stability analysis by rescaling the amplitude of the observed $\bar{U}(y)$ profile, using various constant ( $y$-independent) multiplicative factors, as Philander (1978) did for the Atlantic. Note that the resulting collection of $\bar{U}(y)$ profiles is taken to represent only the gross characteristics of the mean flow; details such as surfacing of the undercurrent on the equator in the spring (Hayes and Halpern, 1984) are not accounted for. In any event, the true applicability of this model analysis is questionable for finite amplitude instabilities, which may themselves modify the mean field.

Two nondimensional parameters control the character of the solution-the Rossby number, Ro $=U_{0} a$ / $2 \Omega L^{2}$, and the Richardson number, $\mathrm{Ri}=g^{*} H / U_{0}^{2}$, where $U_{0}$ is the maximum speed of the zonal mean
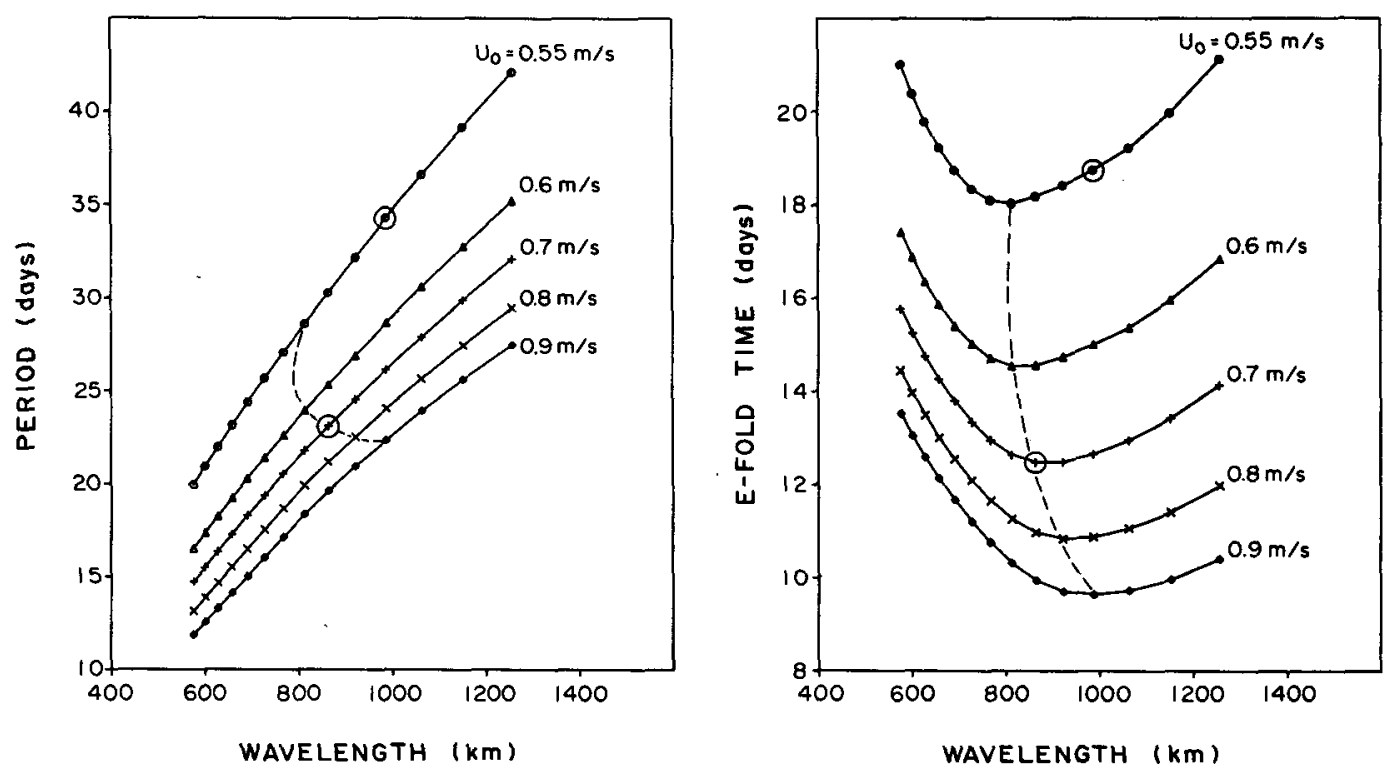

FIG. 15. Period (a) and $e$-folding time (b) of unstable wave as a function of zonal wavelength and maximum mean zonal velocity, $U_{0}$. Center curve $\left(U_{0}=0.7 \mathrm{~m} \mathrm{~s}^{-1}\right)$ corresponds to original Hansen and Paul (1984) profile of mean zonal velocity, $\vec{U}(y)$. Circles indicate dispersion points of 23 - and 34-day waves depicted as $P^{\prime 2}$ in Figs. 10 and 11 , respectively. The dashed lines connect points of most rapid growth. 
flow, $L$ is a measure of the latitudinal width of the shear region, and the other symbols are defined as by Philander (1976).

For consistency with Philander's analysis, we set Ri $=10$ and $L=550 \mathrm{~km}$, and varied Ro by varying $U_{0}$. The dispersion relationships and growth-rate curves are shown in Fig. 15. The center curve in each frame $\left(U_{0}\right.$ $=0.7 \mathrm{~m} \mathrm{~s}^{-1}$ ) corresponds to the observed profile; the curves above and below this correspond to rescalings of the entire $\bar{U}(y)$ profile by up to $30 \%$, as indicated.

The fastest growing wave for the observed $U_{0}=0.7$ $\mathrm{m} \mathrm{s}^{-1}$ profile has period 23 days, zonal wavelength 860 $\mathrm{km}$, and $e$-folding time of about 12 days (as compared to Philander's results of 30 days, $1100 \mathrm{~km}$, and 14 days, respectively, for the Atlantic). Note that the period of most rapid growth (dashed line in Fig. 15a) is insensitive to changes in $U_{0}$, except at relatively small values $\left(U_{0}\right.$ $<0.6 \mathrm{~m} \mathrm{~s}^{-1}$ ); the wavelength of most rapid growth is insensitive to $U_{0}$ for $U_{0}<0.6 \mathrm{~m} \mathrm{~s}^{-1}$ and only slightly sensitive for $U_{0}>0.6 \mathrm{~m} \mathrm{~s}^{-1}$. The circled points on the $0.7 \mathrm{~m} \mathrm{~s}^{-1}$ and $0.55 \mathrm{~m} \mathrm{~s}^{-1}$ curves identify the dispersion points of the $P^{\prime 2}$ eigenfunctions plotted in Figs. 10 and 11 , respectively. Figure $15 \mathrm{~b}$ shows that the $P^{\prime 2}$ curve in Fig. 10 is based on the maximum growth-rate point for the observed $U_{0}=0.7 \mathrm{~m} \mathrm{~s}^{-1}$, while the $P^{\prime 2}$ curve in Fig. 11 is based on a point on the $U_{0}=0.55 \mathrm{~m} \mathrm{~s}^{-1}$ curve for which the growth rate is $95 \%$ of the maximum growth rate.

\section{REFERENCES}

Barnett, T. P., and W. C. Patzert, 1980: Scales of thermal variability in the tropical Pacific. J. Phys. Oceanogr., 10, 529-540.

Cox, M. D., 1980: Generation and propagation of 30-day waves in a numerical model of the Pacific. J. Phys. Oceanogr., 10, 11681186.
Halpern, D., 1982: Low frequency upper ocean current fluctuations at $0^{\circ}, 110^{\circ} \mathrm{W}$. Eos Trans. Amer. Geophys. Union, 63, p. 85 .

Hansen, D. V., and C. A. Paul, 1984: Genesis and effects of long waves in the equatorial Pacific. J. Geophys. Res., 89, 10 43110440.

Hastenrath, S., and P. J. Lamb, 1977: Climatic Atlas of Tropical Atlantic and Eastern Pacific Oceans. The University of Wisconsin Press, $113 \mathrm{pp}$.

Hayes, S. P., and D. Halpern, 1984: Correlation of current and sea level in the eastern equatorial Pacific. J. Phys. Oceanogr., 14, $811-824$.

- - J. M. Toole and L. J. Mangum, 1983: Water mass and transport variability at $110^{\circ} \mathrm{W}$ in the equatorial Pacific. J. Phys. Oceanogr., 13, 153-168.

Leetmaa, A., 1982: Observations of near-equatorial flows in the eastern Pacific. J. Mar. Res., 40(Suppl), 357-370.

Legeckis, R., 1977: Long waves in the eastern equatorial Pacific Ocean: A view from a geostationary satellite. Science, 197, 1179-1181.

,- 1983 : Satellite infrared observations of oceanic long waves in the eastern equatorial Pacific 1975 to 1981 . NOAA Tech. Rep. NESS $92,22 \mathrm{pp}$.

- W. Pichel and G. Nesterczuk, 1983; Equatorial long waves in geostationary satellite observations and in a multichannel sea surface temperature analysis. Bull. Amer. Meteor. Soc., 64, 133139.

Philander, S. G. H., 1976: Instabilities of zonal equatorial currents. J. Geophys. Res., 81, 3725-3735.

- 1978: Instabilities of zonal equatorial currents, 2. J. Geophys. Res., 83, 3679-3682.

Semtner, A. J., and W. R. Holland, 1980: Numerical simulation of equatorial ocean circulation. Part I: A basic case in turbulent equilibrium. J. Phys. Oceanogr., 10, 667-693.

Tsuchiya, M., 1974: Variations of the surface geostrophic flow in the eastern tropical Pacific Ocean. Fish. Bull., 72, 1075-1086.

Watts, D. R., and H. T. Rossby, 1977: Measuring dynamic heights with inverted echo sounders: Results from MODE. J. Phys. Oceanogr., 7, 345-358.

Weisberg, R. H., A. Horigan and C. Colin, 1979: Equatorially trapped Rossby-gravity wave propagation in the Gulf of Guinea. J. Mar. Res., 37, 67-86.

Wyrtki, K., 1964: The thermal structure of the eastern Pacific Ocean. Dtsch. Hydrogr. Z., A6, 84 pp.

- 1978: Lateral oscillations of the Pacific equatorial countercurrent. J. Phys. Oceanogr., 8, 530-532. 